\title{
Bacterial diversity in the sediment of Crescent Moon Spring, Kumtag Desert, Northwest China
}

\author{
ZHANG Wei ${ }^{1,2}$, ZHANG Gaosen ${ }^{1,2}$, WU Xiukun ${ }^{1,2}$, LIU Guangxiu ${ }^{1,2^{*}}$, DONG Zhibao ${ }^{1,2}$, \\ QU Jianjun ${ }^{1,2,3}$, WANG Yun ${ }^{1,2}$, CHEN Tuo ${ }^{1,2}$ \\ ${ }^{1}$ Key Laboratory of Desert and Desertification, Northwest Institute of Eco-Environment and Resources, Chinese Academy of \\ Sciences, Lanzhou 730000, China; \\ ${ }^{2}$ Gansu Key Laboratory of Extreme Environmental Microbial Resources and Engineering, Lanzhou 730000, China; \\ ${ }^{3}$ Dunhuang Gobi and Desert Ecology and Environment Research Station, Northwest Institute of Eco-Environment and \\ Resources, Chinese Academy of Sciences, Dunhuang 736200, China
}

\begin{abstract}
Desert lake, a unique oasis in desert ecosystems, harbours different bacterial communities. Thus, it is considered as a hub of bacterial diversity. In this study, bacterial diversity in the sediment of Crescent Moon Spring, Kumtag Desert, Northwest China was analyzed using high-throughput amplicon pyrosequencing analysis. The sequences of the most abundant OUTs (Operational Taxonomic Units) in the sediment of Crescent Moon Spring were compared with the sequences of those most abundant OUTs of various origins from NCBI GenBank database to detect the origins of bacteria in the sediment of Crescent Moon Spring. Also, bacterial compositions between sediment of Crescent Moon Spring and other desert and lake ecosystems (including desert lakes) worldwide were compared using cluster analysis to determine the possible factors affecting bacterial compositions. In total, 11,855 sequences were obtained and 30 phyla were identified. At the phylum level, the dominant phylum was Proteobacteria with $\alpha$-Proteobacteria being the first dominant class and the second dominant phylum was Planctomycetes. Our finding that $\alpha$-Proteobacteria being the first dominant class of Proteobacteria and Planctomycetes being the second dominant phyla are somewhat contradictory with reports from other desert lake sediments. This difference could be resulted from water hydration and conductivity, as well as oligotrophic conditions of Crescent Moon Spring. At the genus level, Rhodobacter, Caldilinea, Planctomyces, and Porphyrobacter were the dominant genera in the sediment of Crescent Moon Spring. Comparisons on sequences of the most abundant OUTs (including OTU3615, OTU6535, and OTU6646) between sediment of Crescent Moon Spring and various origins from NCBI GenBank database indicate that the origins of bacteria in the sediment of Crescent Moon Spring are likely from the underground water. Furthermore, cluster analysis on comparisons of bacteria compositions between sediment of Crescent Moon Spring and other desert and lake ecosystems (including desert lakes) worldwide shows that at regional scales, bacterial compositions may be mainly affected by geographical patterns, precipitation amounts, and $\mathrm{pH}$ values. Collectively, our results provide new knowledge on the bacterial diversity in desert lake ecosystems.
\end{abstract}

Keywords: bacterial diversity; pyrosequencing analysis; desert lake; desert and lake ecosystems; Crescent Moon Spring

Citation: ZHANG Wei, ZHANG Gaosen, WU Xiukun, LIU Guangxiu, DONG Zhibao, QU Jianjun, WANG Yun, CHEN Tuo. 2017. Bacterial diversity in the sediment of Crescent Moon Spring, Kumtag Desert, Northwest China. Journal of Arid Land, 9(2): 278-286. doi: 10.1007/s40333-017-0052-0

\section{Introduction}

As a result of human adverse impacts and climate changes, ecosystems in arid and semi-arid

*Corresponding author: LIU Guangxiu (E-mail: liugx@1zb.ac.cn)

Received 2015-12-23; revised 2016-11-29; accepted 2016-12-10

(C) Xinjiang Institute of Ecology and Geography, Chinese Academy of Sciences, Science Press and Springer-Verlag Berlin Heidelberg 2017 
regions are rapidly losing biodiversity (including plants, animals, and microbes) at taxonomic, phylogenetic, genetic, and functional levels (Naeem et al., 2012). Undoubtedly, biodiversity is critically important to maintaining the health and stability of various ecosystems in arid and semi-arid regions. The desert ecosystem stands out in terms of maintaining its biodiversity because it is naturally fragile (He et al., 2016). Compared to other ecosystems (e.g., grassland, farmland, and forest ecosystems) in arid and semi-arid regions, the growth or flourishment of living organisms in desert ecosystems is seriously impeded by harsh environment conditions (Azua-Bustos et al., 2012). Even so, a higher microbial diversity was repeatedly reported from desert ecosystems (Skujinš, 1984; Chanal et al., 2006; Orlando et al., 2010; Saul-Tcherkas and Steinberger, 2011; Zhang et al., 2012; Eldridge et al., 2015; McCann et al., 2016). Desert lake is definitely considered as a hub of biodiversity in desert ecosystems. Many studies assessed the growth and diversity of microbes in desert lakes either using culture-dependent method (Hedi et al., 2009; Rohban et al., 2009) or using culture-independent method (Zeglin et al., 2011; He et al., 2015). A number of studies have already indicated that desert lakes may harbour different bacterial and archaeal communities from halotolerant to extremely halophilic organisms (Dong et al., 2006; Navarro et al., 2009; Bhatt et al., 2016).

This study focuses on Crescent Moon Spring (actually a desert lake) situated at the southern edge of the Kumtag Desert, the latter (i.e., Kumtag Desert) being located at the south of the Lop Nor and north of the Altun Mountains (Dong et al., 2010). Crescent Moon Spring owes its name to the shape (i.e., looks like a crescent moon) and is fed by spring water (Jiao, 2010). Due to excessive exploitation of groundwater and intensive agricultural activities in the region, the Crescent Moon Spring has shrunken considerably in recent years (Dong, 2007). Consequently, bacterial biodiversity loss has inevitably occurred in the Crescent Moon Spring. To protect the local biodiversity, it is essential to understanding the bacterial composition as well as its influencing factors in the Crescent Moon Spring (Cai and Cheng, 1990; Gans et al., 2005; Wessén et al., 2011). In this study, bacterial diversity in the sediment of Crescent Moon Spring was assessed using high-throughput amplicon pyrosequencing analysis. The aims of this study were to: (1) quantitatively analyze the bacterial diversity in the sediment; (2) qualitatively detect the origins of bacteria by comparing the sequences of the most abundant OUTs (Operational Taxonomic Units) in the sediment of Crescent Moon Spring with the sequences of those most abundant OUTs in various origins from NCBI GenBank database; and (3) qualitatively identify the environmental factors affecting bacterial compositions by comparing bacterial composition in the sediment of Crescent Moon Spring with bacterial compositions in the other desert and lake ecosystems (including desert lakes) worldwide.

\section{Materials and methods}

\subsection{Study area}

Crescent Moon Spring $\left(40^{\circ} 05^{\prime} \mathrm{N}, 94^{\circ} 40^{\prime} \mathrm{E}\right)$, a desert lake, is a geological wonder approximately 6 $\mathrm{km}$ south of Dunhuang City, Gansu Province, Northwest China (Fig. 1a). Currently, the Crescent Moon Spring is approximately $200 \mathrm{~m}$ in length and $50 \mathrm{~m}$ in width. The mean annual precipitation is less than $40 \mathrm{~mm}$ while the potential evaporation is greater than $2400 \mathrm{~mm}$ (Jiao, 2010).

\subsection{Field sampling}

In July 2010, five sediment cores were randomly collected, using a hand-operated sediment corer with 100-mm internal diameter, from five different sites along the lakeshore (Fig. 1b). The upper $10-\mathrm{cm}$ layer of those five sediment cores was mixed, packed in airtight bottles, and then transported to the laboratory under ice cooling, and frozen at $-70^{\circ} \mathrm{C}$ in refrigerator (Roesch et al., 2007). During sediment sampling, five water samples were simultaneously collected at the depth of $0-50 \mathrm{~cm}$ with plastic bottles from those five sites to analyze the $\mathrm{pH}$. The $\mathrm{pH}$ was measure by a $\mathrm{pH}$ metre (PT-10, Sartorius, Germany), and the mean $\mathrm{pH}$ of Crescent Moon Spring water was $8.24( \pm 0.01)$. 


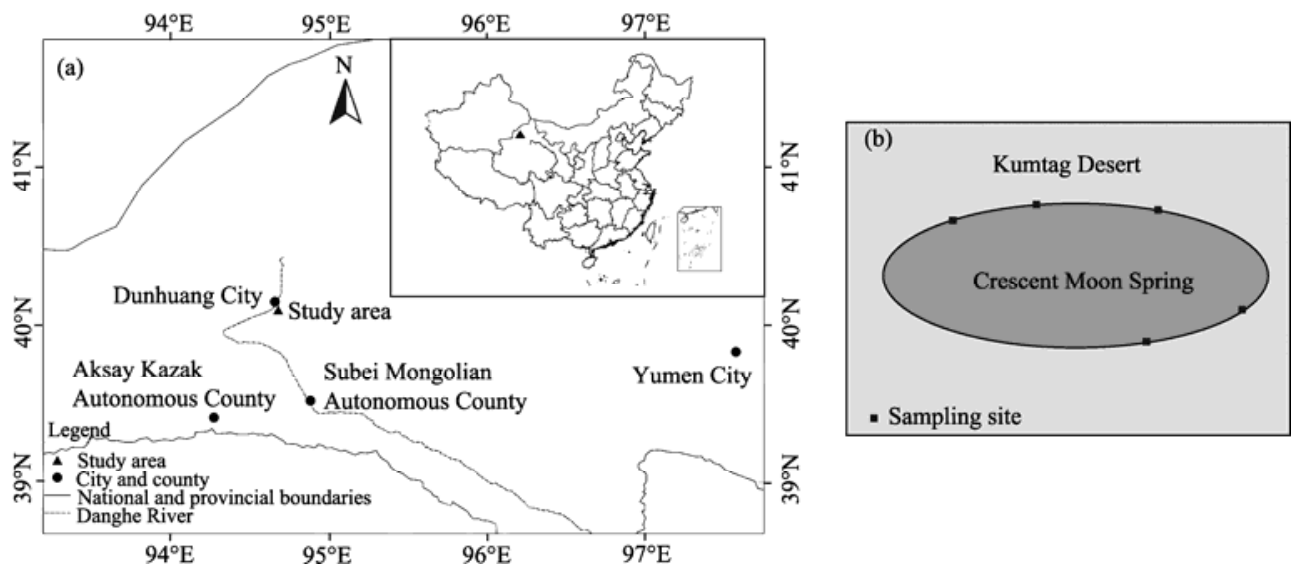

Fig. 1 Location of the study area (a) and sketch map of the sampling sites (b)

\subsection{DNA (deoxyribonucleic acid) extraction, PCR (polymerase chain reaction) and bar-coded pyrosequencing}

In the laboratory, genomic DNA was isolated from at least $1 \mathrm{~g}$ of mixed sediment using the PowerSoil DNA Isolation Kit (MoBio Laboratories, Carlsbad, CA, USA). Integrity of the extracted DNA was checked on a $1 \%$ agarose gel, and the concentration was measured using a Nanodrop ND-1000 UV-Vis Spectrophotometer (Nano-Drop Technologies, Wilmington, DE). The eluted DNA was stored at $-20^{\circ} \mathrm{C}$.

The 16S rRNA (ribosomal RNA) gene fragments of the appropriate size were amplified using the primers B27F (5'-AGAGTTTGATCCTGGCTCAG-3', Escherichia coli position 9-27) and B515R (5'-TTACCGCGGCTGCTGGCAC-3', E. coli position 533-515) (Watanabe et al., 2009). Using these primers, the V1-V3 region of the 16S rRNA genes were amplified from bacterial DNA presented in the sediment DNA samples. Each PCR contained $2.0 \mu \mathrm{L}$ of $10 \times$ buffer, $1.6 \mu \mathrm{L}$ of dNTP, $0.8 \mu \mathrm{L}$ of forward primer B27F, $0.8 \mu \mathrm{L}$ of reverse primer B515R, and $0.8 \mu \mathrm{L}$ of Pfu Taq DNA polymerase (1.0 U per reaction). Thermal cycling conditions consisted of an initial denaturation cycle at $94^{\circ} \mathrm{C}$ for $3 \mathrm{~min}$, followed by 25 cycles of denaturation at $94^{\circ} \mathrm{C}$ for $30 \mathrm{~s}$, annealing at $50^{\circ} \mathrm{C}$ for $30 \mathrm{~s}$, an extension at $72^{\circ} \mathrm{C}$ for $30 \mathrm{~s}$ and a final extension at $72^{\circ} \mathrm{C}$ for $10 \mathrm{~min}$.

Amplicons were purified using the AxyPrep DNA Gel Extraction Kit (Axygen, CA, USA). Concentrations of the purified amplicons were quantified using the TBS-380 system, and equal amounts of all amplicons were mixed in a single tube. Emulsion PCR was performed on the pooled amplicons as described by Margulies et al. (2005), and sequencing was conducted using a GS FLX Titanium System (454 Life Sciences, Roche Applied Science, USA).

\subsection{Phylogenetic assignment, alignment and clustering of 16S rRNA gene fragments}

Sequence reads were filtered using the following criteria: (i) a perfect match to the $16 \mathrm{~S}$ rRNA gene primer; (ii) >200 bases in length; and (iii) no undetermined bases. Reads passing all filters were used to identify phylotypes using Megablast, and the representative sequence from each phylotype was aligned using the SILVA database (Pruesse et al., 2007). In microbial diversity studies, various thresholds of sequence similarity among 16S rRNA gene sequences are commonly used as a proxy for different taxonomic levels. In this study, sequence similarity levels of $90 \%, 95 \%$, and $97 \%$ were used to assign different phyla, genera, and species, respectively (Roesch et al., 2007; Oakley et al., 2008). The quality of sequencing reads were assessed following the criteria described by Sogin et al. (2006) and McKenna et al. (2008).

\subsection{Statistical analysis}

OTUs (Operational Taxonomic Units), Chao1 index and Ace index for richness, Shannon index for diversity, and Simpson index and Smith-Wilson index for evenness were calculated at dissimilarity levels of 3\%, 5\%, and 10\% using DOTUR software (Roesch et al., 2007). SPSS software was used for the cluster analysis. 


\section{Results}

In total, 11,855 valid sequences were obtained by pyrosequencing (Table 1). Resulting coverages were $92.57 \%, 88.10 \%$, and $85.20 \%$ at similarity levels of $90 \%, 95 \%$, and $97 \%$, respectively. The high coverage values $(>85 \%)$ indicated that the pyrosequencing results were reliable.

Table 1 Pyrosequencing reads and richness, diversity and evenness estimators for the bacteria in the sediment of Crescent Moon Spring

\begin{tabular}{ccccccccc}
\hline \multirow{2}{*}{ Reads } & $\begin{array}{c}\text { Similarity } \\
\text { level (\%) }\end{array}$ & Coverage (\%) & OTUs & $\begin{array}{c}\text { Ace } \\
\text { index }\end{array}$ & $\begin{array}{c}\text { Chaol } \\
\text { index }\end{array}$ & $\begin{array}{c}\text { Shannon } \\
\text { index }\end{array}$ & $\begin{array}{c}\text { Simpson } \\
\text { index }\end{array}$ & $\begin{array}{c}\text { Smith-Wilson } \\
\text { index }\end{array}$ \\
\hline \multirow{3}{*}{11,855} & 97 & 85.20 & 3139 & 8894 & 6200 & 7.15 & 0.0023 & 0.0871 \\
& 95 & 88.10 & 2763 & 6662 & 4935 & 6.96 & 0.0027 & 0.1561 \\
& 90 & 92.57 & 2045 & 3866 & 3096 & 6.55 & 0.0038 & 0.2554 \\
\hline
\end{tabular}

Note: OTUs, Operational Taxonomic Units.

At the phylum level, a total of 30 phyla were detected (Table 2). Proteobacteria was the first dominant phylum with relative abundance of $41.54 \%$. Specifically, it could be further classified into five classes, i.e., $\alpha$-, $\beta$-, $\gamma$-, $\delta$-, and $\varepsilon$-Proteobacteria. The $\alpha$-Proteobacteria had the highest relative abundance, reaching up to $29.06 \%$, thus it was the dominant class. The second dominant phylum was Planctomycetes, with relative abundance of $15.07 \%$. Furthermore, the other important phyla with relative abundance greater than $1 \%$ were Chloroflexi, Bacteroidetes, Verrucomicrobia, Firmicutes, Cyanobacteria, Acidobacteria, Actinobacteria, OP10, and Gemmatimonadetes.

At the genus level, a total of 333 genera were identified, with relative abundance accounting for $48.69 \%$ of the total genera. It should be pointed out that genera with relative abundance of $51.31 \%$ were not identified (i.e., unclassified genera) and only the dominant genera with relative abundance of $>1 \%$ were listed in Table 2. Rhodobacter, Caldilinea, Planctomyces, and Porphyrobacter were the dominant genera, with relative abundance of $>2 \%$ for each. Furthermore, Gemmata, Pirellula, Fusibacter, Hyphomicrobium, Chthoniobacter, and Lewinella were also the important genera, with relative abundance of $1 \%-2 \%$ for each.

As shown in Table 1, there were 3139 OTUs at the $97 \%$ sequence similarity level. And, OTU3615, OTU6535, and OTU6646 were the most abundant OTUs, with 305, 194, and 106 sequences, respectively (see Table 3). By comparing the sequences of OTU3615, OTU6535, OTU6646 in the sediment of Crescent Moon Spring with the sequences of those abundant OUTs in various origins from NCBI GenBank database (http://www.nvbi.nlm.nih.gov), it can be found that there were several similar sequences between sediment of Crescent Moon Spring and other water systems in the world, including freshwater, seawater, lake water, etc. (see Table 3). It should be added that this comparison could be used to detect the bacterial origins of Crescent Moon Spring. Comparisons on sequences of OTU3615, OTU6535, and OTU6646 between sediment of Crescent Moon Spring and various origins from NCBI GenBank database indicate that the origins of bacteria in the sediment of Crescent Moon Spring are likely from the underground water.

\section{Discussion}

Bacterial communities are recognized as the major contributors to soil function (Uroz et al., 2010). In this study, a total of 30 bacterial phyla were found in the sediment of Crescent Moon Spring, providing new knowledge on the bacterial diversity in desert lake ecosystems. Proteobacteria, with relative abundance of $41.54 \%$, was the first dominant phylum in the sediment of Crescent Moon Spring. Although some studies argued that Proteobacteria could be the most abundant 
Table 2 Relative abundances of bacterial phyla, classes and genera in the sediment of Crescent Moon Spring

\begin{tabular}{|c|c|c|c|c|c|}
\hline Phylum & $\begin{array}{c}\text { Relative } \\
\text { abundance }(\%)\end{array}$ & Class & $\begin{array}{c}\text { Relative } \\
\text { abundance }(\%)\end{array}$ & Genus & $\begin{array}{c}\text { Relative } \\
\text { abundance }(\%)\end{array}$ \\
\hline Proteobacteria & 41.54 & $\alpha$-Proteobacteria & 29.06 & Rhodobacter & 2.86 \\
\hline Planctomycetes & 15.07 & $\beta$-Proteobacteria & 4.94 & Caldilinea & 2.81 \\
\hline Chloroflexi & 8.93 & $\delta$-Proteobacteria & 3.92 & Planctomyces & 2.32 \\
\hline Bacteroidetes & 8.39 & $\gamma$-Proteobacteria & 3.61 & Porphyrobacter & 2.05 \\
\hline Verrucomicrobia & 6.33 & $\varepsilon$-Proteobacteria & 0.01 & Gemmata & 1.95 \\
\hline Firmicutes & 4.31 & Planctomycetacia & 11.77 & Pirellula & 1.76 \\
\hline Cyanobacteria & 3.74 & Sphingobacteria & 7.22 & Fusibacter & 1.55 \\
\hline Acidobacteria & 3.32 & Clostridia & 4.11 & Hyphomicrobium & 1.50 \\
\hline Actinobacteria & 2.99 & Caldilineae & 3.94 & Chthoniobacter & 1.47 \\
\hline OP10 & 1.37 & Verrucomicrobiae & 3.87 & Lewinella & 1.19 \\
\hline Gemmatimonadetes & 1.11 & Anaerolineae & 3.26 & Others & 29.23 \\
\hline OD1 & 0.72 & Actinobacteria & 2.99 & $\begin{array}{l}\text { Unassigned } \\
\text { sequences }\end{array}$ & 51.31 \\
\hline Nitrospirae & 0.38 & Chloroplast & 2.78 & & \\
\hline BRC1 & 0.35 & Acidobacteria & 2.72 & & \\
\hline TM6 & 0.32 & Phycisphaerae & 2.63 & & \\
\hline Chlorobi & 0.21 & Spartobacteria & 1.76 & & \\
\hline Fusobacteria & 0.16 & Gemmatimonadetes & 1.11 & & \\
\hline TM7 & 0.13 & Others & 6.62 & & \\
\hline WS3 & 0.12 & $\begin{array}{l}\text { Unassigned } \\
\text { sequences }\end{array}$ & 3.68 & & \\
\hline Spirochaetes & 0.10 & & & & \\
\hline Lentisphaerae & 0.09 & & & & \\
\hline Aquificae & 0.08 & & & & \\
\hline Deinococcus-Thermus & 0.06 & & & & \\
\hline OP 11 & 0.05 & & & & \\
\hline OP3 & 0.05 & & & & \\
\hline Elusimicrobia & 0.03 & & & & \\
\hline SR1 & 0.02 & & & & \\
\hline Fibrobacteres & 0.01 & & & & \\
\hline GOUTA4 & 0.01 & & & & \\
\hline SM2F11 & 0.01 & & & & \\
\hline
\end{tabular}

bacterial group in desert ecosystems (Chanal et al., 2006; Zhang et al., 2012), Actinobacteria was found to be the dominant phylum in some deserts such as Atacama Desert, Negev Desert, and McMurdo Dry Valleys of Antarctica, etc. (Fierer et al., 2009; Pointing et al., 2009; Orlando et al., 2010; Saul-Tcherkas and Steinberger, 2011; Neilson et al., 2012; Wang et al., 2012). As shown in Table 2, Actinobacteria was less abundant in the sediment of Crescent Moon Spring. It should be particularly pointed out that $\alpha$-Proteobacteria with relative abundance of $29.06 \%$ was the first dominant class of Proteobacteria in the sediment of Crescent Moon Spring. This result is contradictory with those from many other desert and lake ecosystems (including desert lakes). For example, $\gamma$-Proteobacteria was considered as the first dominant class of Proteobacteria in the warmer Chihuahuan Desert, New Mexico, USA (Zeglin et al., 2011). Generally, the difference in the first dominant class of phylum Proteobacteria among different desert and lake ecosystems (including desert lakes) could be explained by the differences in water hydration and conductivity (Zeglin et al., 2011).

In the sediment of Crescent Moon Spring, Planctomycetes was the second dominant phylum, with high relative abundance of $15.07 \%$. This finding is somewhat contradictory with reports from other desert lake sediments. For example, Planctomycetes was negligible in saline lake sediments in southern Australia (Abed et al., 2012) and in Tibetan Plateau of China (Xiong et al., 2012). Under eutrophic conditions (i.e., sufficient nutrient concentrations), the growth of bacteria with slow-response to nutrient supply is slower than the growth of bacteria with high-response to 


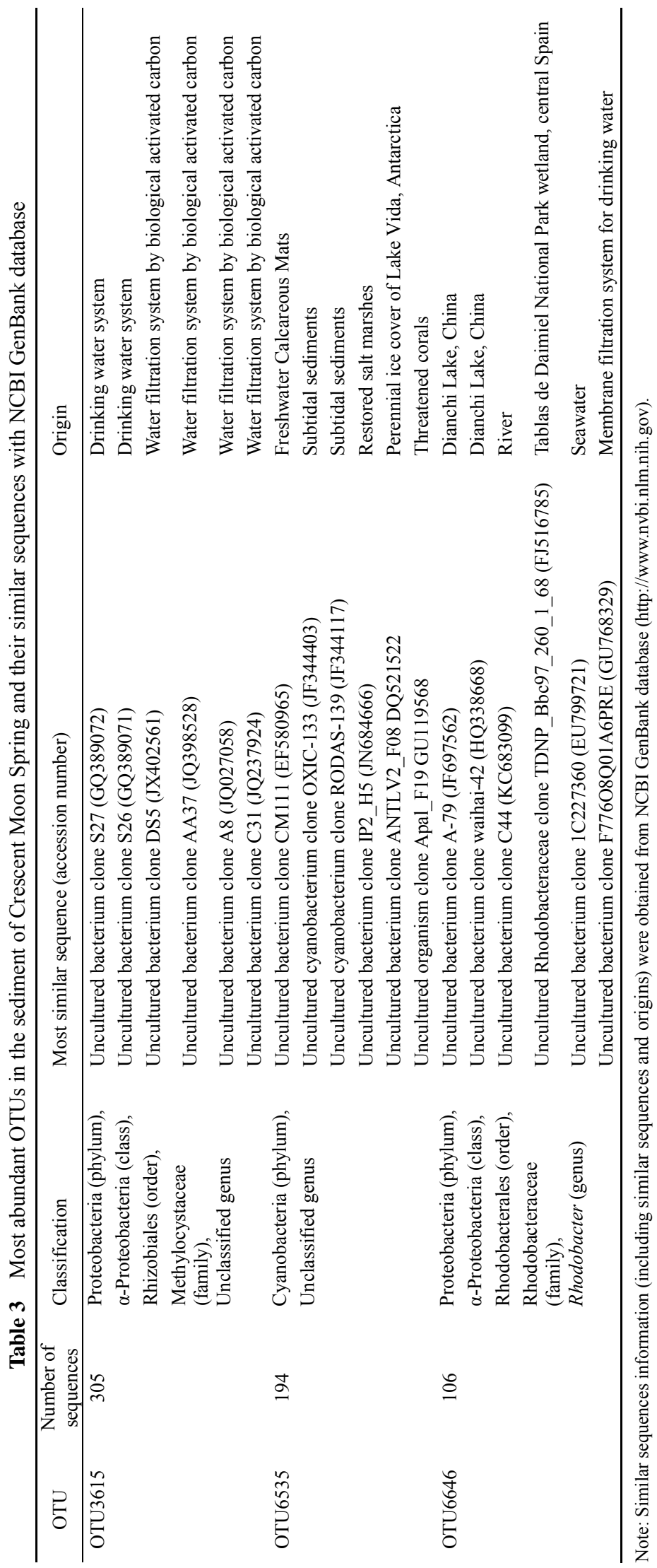


nutrient supply in lake ecosystems due to rapid growth-promoting competition between individuals, where stronger competitors may exclude others which have overlapping niches, resulting in low relative abundance of bacteria with slow-response to nutrient supply. Under oligotrophic conditions (i.e., insufficient nutrient concentrations), however, the environmental conditions are more favorable to bacteria with low-response to nutrient supply, resulting in high relative abundance of bacteria with low-response to nutrient supply (Song et al., 2016). It was recently reported that Planctomycetes could not respond quickly to the nutrient supply in lake ecosystems, i.e., bacteria with slow-response to nutrient supply (Pollet et al., 2014). The high relative abundance of Planctomycetes in the sediment of Crescent Moon Spring may be due to the oligotrophic conditions in this unique desert lake. As mentioned above, the predominance of $\alpha$-Proteobacteria in the class of Proteobacteria and the high relative abundance of Planctomycetes were the main differences between sediment of Crescent Moon Spring and many other desert and lake ecosystems (including desert lakes) worldwide.

The cluster analysis, based on the relative abundance of bacterial phyla, could provide additional information for comparing the bacterial compositions between sediment of Crescent Moon Spring and other desert and lake ecosystems (including desert lakes) worldwide. As shown in Figure 2, bacterial composition in the sediment of Crescent Moon Spring was similar to bacterial compositions in the deserts in Linze of China (Wang et al., 2012) and Egypt (Köberl et al., 2011) and dissimilar to bacterial compositions in the Atacama Desert (Neilson et al., 2012) and in the desert oasis of Cuatro Cienegas Basin (López-Lozano et al., 2013). The desert in Linze is geographically close to the Crescent Moon Spring, approximately $500 \mathrm{~km}$ away (Wang et al., 2012), so geographical proximity may explain the observed similarity. The similarity of bacterial compositions between sediment of Crescent Moon Spring and desert in Egypt may be due to the similar mean annual precipitation amount, i.e., $40 \mathrm{~mm}$ in the Crescent Moon Spring (Jiao, 2010) and 21-52 $\mathrm{mm}$ in the desert of Egypt (Köberl et al., 2011). However, the mean annual precipitation amounts in the desert oasis of Cuatro Cienegas Basin and in the Atacama Desert are significantly different from that in the Crescent Moon Spring. The desert oasis in Cuatro Cienegas Basin is a representative desert region with high precipitation, reaching up to $1500 \mathrm{~mm}$ (López-Lozano et al., 2013) and Atacama Desert is a representative desert region with low precipitation, as low as $<20 \mathrm{~mm}$ (Neilson et al., 2012). Generally, microbial activity in desert ecosystems is closely related to short-period water availability, which may in turn affect the overall microbial diversity (Bhatnagar and Bhatnagar, 2005; Shamir and Steinberger, 2007). Thus, we argue that precipitation is one of the important factors affecting bacterial compositions at regional scales. Additionally, bacterial composition in the sediment of Crescent Moon Spring was similar to the bacterial compositions in the sediments of neutral and slightly alkaline lakes in Tibetan Plateau of China (Xiong et al., 2012; Fig. 2) and the similarity could be explained by the similar $\mathrm{pH}$ values.

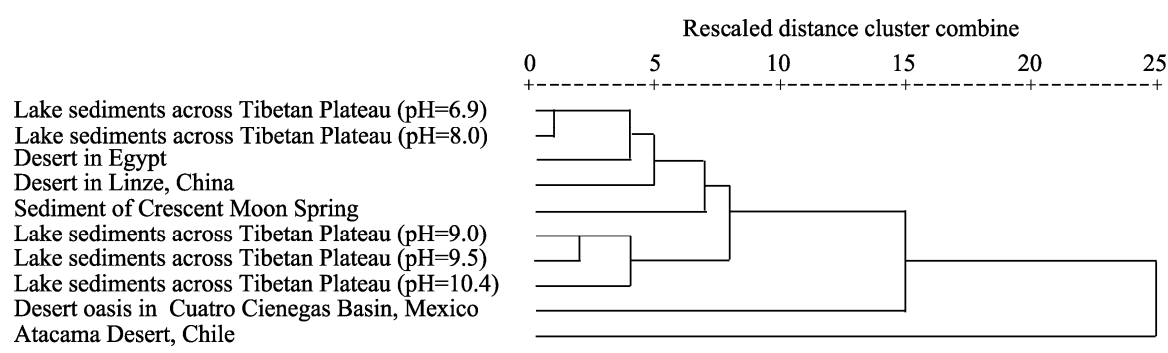

Fig. 2 Cluster analysis on bacterial compositions between sediment of Crescent Moon Spring and other desert and lake ecosystems based on relative phyla abundance

\section{Conclusions}

In this study, bacterial diversity in the sediment of Crescent Moon Spring, Kumtag Desert of Northwest China was assessed using high-throughput amplicon pyrosequencing analysis. A total 
of 30 bacterial phyla were identified in the sediment, with Proteobacteria being the first dominant phyla ( $\alpha$-Proteobacteria being the first dominant class) and Planctomycetes being the second dominant phyla, providing new knowledge on the bacterial diversity in desert lake ecosystems. Comparisons of bacteria compositions between sediment of Crescent Moon Spring and other desert and lake ecosystems (including desert lakes) worldwide show that at regional scales, bacterial compositions may be mainly affected by geographical patterns, precipitation amounts, and $\mathrm{pH}$ values. Furthermore, we speculate that the origins of bacterial in the sediment of Crescent Moon Spring are likely from the underground water. Our speculation was based on the comparison of the sequences between the most abundant OUTs in the sediment of Crescent Moon Spring and the abundant OUTs in various origins from NCBI GenBank database.

\section{Acknowledgments}

This study was supported by the National Natural Science Foundation of China (41271265, 31570498, 31300411), the Science and Technology Projects in Gansu Province (1304NKCA135), and the Foundation of China Scholarship Council.

\section{References}

Abed R M M, Ramette A, Hübner V, et al. 2012. Microbial diversity of eolian dust sources from saline lake sediments and biological soil crusts in arid Southern Australia. FEMS Microbiology Ecology, 80(2): 294-304.

Azua-Bustos A, Urrejola C, Vicuña R. 2012. Life at the dry edge: microorganisms of the Atacama Desert. FEBS Letters, 586(18): 2939-2945.

Bhatnagar A, Bhatnagar M. 2005. Microbial diversity in desert ecosystems. Current Science, 89(1): 91-100.

Bhatt H H, Pasricha R, Upasani V N. 2016. Isolation and characterization of a halophilic cyanobacterium Euhalothece SLVH01 from Sambhar salt lake, India. International Journal of Current Microbiology and Applied Sciences, 5(2): $215-224$.

Cai H Z, Cheng Z J. 1990. Some blue-green algae collected from the Crescent Moon Spring in Dunhuang. Journal of Northwest Normal University, (4): 60-63. (in Chinese)

Chanal A, Chapon V, Benzerara K, et al. 2006. The desert of Tataouine: an extreme environment that hosts a wide diversity of microorganisms and radiotolerant bacteria. Environmental Microbiology, 8(3): 514-525.

Dong H L, Zhang G X, Jiang H C, et al. 2006. Microbial diversity in sediments of saline Qinghai Lake, China: linking geochemical controls to microbial ecology. Microbial Ecology, 51(1): 65-82.

Dong J H. 2007. Investigation on the degradation of natural heritage of Singing Sand Mountain and Crescent Moon Spring at Dunhuang city, China. Chinese Journal of Population Resources and Environment, 5(4): 85-91.

Dong Z B, Qian G G, Yan P, et al. 2010. Gravel bodies in the Kumtagh Desert and their geomorphological implications. Environmental Earth Sciences, 59(8): 1771-1779.

Eldridge D J, Woodhouse J N, Curlevski N J A, et al. 2015. Soil-foraging animals alter the composition and co-occurrence of microbial communities in a desert shrubland. The ISME Journal, 9(12): 2671-2681.

Fierer N, Strickland M S, Liptzin D, et al. 2009. Global patterns in belowground communities. Ecology Letters, 12(11): 1238-1249.

Gans J, Wolinsky M, Dunbar J. 2005. Computational improvements reveal great bacterial diversity and high metal toxicity in soil. Science, 309(5739): 1387-1390.

He K J, Qi Y, Huang Y M, et al. 2016. Response of aboveground biomass and diversity to nitrogen addition-a five-year experiment in semi-arid grassland of Inner Mongolia, China. Scientific Reports, 6: 31919.

He X M, Lv G H, Qin L, et al. 2015. Effects of simulated nitrogen deposition on soil respiration in a Populus euphratica community in the Ebinur Lake area, a desert ecosystem of northwestern China. PLoS ONE, 10(9): e0137827, doi: 10.1371/journal.pone.0137827.

Hedi A, Sadfi N, Fardeau M L, et al. 2009. Studies on the biodiversity of halophilic microorganisms isolated from El-Djerid Salt Lake (Tunisia) under aerobic conditions. International Journal of Microbiology, 2009, 731786, doi: $10.1155 / 2009 / 731786$.

Jiao J J. 2010. Crescent Moon Spring: a disappearing natural wonder in the Gobi desert, China. Groundwater, 48(1): $159-163$.

Köberl M, Müller H, Ramadan E M, et al. 2011. Desert farming benefits from microbial potential in arid soils and promotes diversity and plant health. PLoS ONE, 6(9): e24452, doi: 10.1371/journal.pone.0024452.

López-Lozano N E, Heidelberg K B, Nelson W C, et al. 2013. Microbial secondary succession in soil microcosms of a desert 
oasis in the Cuatro Cienegas Basin, Mexico. PeerJ, 1: e47.

Margulies M, Egholm M, Altman W E, et al. 2005. Genome sequencing in open microfabricated high-density picolitre reactors. Nature, 437(7057): 376-380.

McCann C M, Wade M J, Gray N D, et al. 2016. Microbial communities in a high arctic polar desert landscape. Frontiers in Microbiology, 7: 419.

McKenna P, Hoffmann C, Minkah N, et al. 2008. The macaque gut microbiome in health, lentiviral infection, and chronic enterocolitis. PLoS Pathogens, 4(2): e20.

Naeem S, Duffy J E, Zavaleta E. 2012. The functions of biological diversity in an age of extinction. Science, 336(6087): 1401-1406.

Navarro J B, Moser D P, Flores A, et al. 2009. Bacterial succession within an ephemeral hypereutrophic Mojave Desert playa Lake. Microbial Ecology, 57(2): 307-320.

Neilson J W, Quade J, Ortiz M, et al. 2012. Life at the hyperarid margin: novel bacterial diversity in arid soils of the Atacama Desert, Chile. Extremophiles, 16(3): 553-566.

Oakley B B, Fiedler T L, Marrazzo J M, et al. 2008. Diversity of human vaginal bacterial communities and associations with clinically defined bacterial vaginosis. Applied and Environmental Microbiology, 74(15): 4898-4909.

Orlando J, Alfaro M, Bravo L, et al. 2010. Bacterial diversity and occurrence of ammonia-oxidizing bacteria in the Atacama Desert soil during a "desert bloom" event. Soil Biology and Biochemistry, 42(7): 1183-1188.

Pointing S B, Chan Y, Lacap D C, et al. 2009. Highly specialized microbial diversity in hyper-arid polar desert. Proceedings of the National Academy of Sciences of the United States of America, 106(47): 19964-19969.

Pollet T, Humbert J F, Tadonléké R D. 2014. Planctomycetes in lakes: poor or strong competitors for phosphorus? Applied and Environmental Microbiology, 80(3): 819-828.

Pruesse E, Quast C, Knittel K, et al. 2007. SILVA: a comprehensive online resource for quality checked and aligned ribosomal RNA sequence data compatible with ARB. Nucleic Acids Research, 35(21): 7188-7196.

Roesch L F W, Fulthorpe R R, Riva A, et al. 2007. Pyrosequencing enumerates and contrasts soil microbial diversity. The ISME Journal, 1(4): 283-290.

Rohban R, Amoozegar M A, Ventosa A. 2009. Screening and isolation of halophilic bacteria producing extracellular hydrolyses from Howz Soltan Lake, Iran. Journal of Industrial Microbiology \& Biotechnology, 36(3): 333-340.

Saul-Tcherkas V, Steinberger Y. 2011. Soil microbial diversity in the vicinity of a Negev Desert shrub—Reaumuria negevensis. Microbial Ecology, 61(1): 64-81.

Shamir I, Steinberger Y. 2007. Vertical distribution and activity of soil microbial population in a sandy desert ecosystem. Microbial Ecology, 53(2): 340-347.

Skujinš J. 1984. Microbial ecology of desert soils. In: Marshall K C. Advances in Microbial Ecology. New York: Springer, 49-91.

Sogin M L, Morrison H G, Huber J A, et al. 2006. Microbial diversity in the deep sea and the underexplored "rare biosphere". Proceedings of the National Academy of Sciences of the United States of America, 103(32): 12115-12120.

Song W, Kim M, Tripathi B M, et al. 2016. Predictable communities of soil bacteria in relation to nutrient concentration and successional stage in a laboratory culture experiment. Environmental Microbiology, 18(6): 1740-1753.

Uroz S, Buée M, Murat C, et al. 2010. Pyrosequencing reveals a contrasted bacterial diversity between oak rhizosphere and surrounding soil. Environmental Microbiology Reports, 2(2): 281-288.

Wang B Z, Zhang C X, Liu J L, et al. 2012. Microbial community changes along a land-use gradient of desert soil origin. Pedosphere, 22(5): 593-603.

Watanabe K, Nagao N, Toda T, et al. 2009. The dominant bacteria shifted from the order "Lactobacillales" to Bacillales and Actinomycetales during a start-up period of large-scale, completely-mixed composting reactor using plastic bottle flakes as bulking agent. World Journal of Microbiology and Biotechnology, 25(5): 803-811.

Wessén E, Söderström M, Stenberg M, et al. 2011. Spatial distribution of ammonia-oxidizing bacteria and archaea across a 44-hectare farm related to ecosystem functioning. The ISME Journal, 5(7): 1213-1225.

Xiong J B, Liu Y Q, Lin X G, et al. 2012. Geographic distance and $\mathrm{pH}$ drive bacterial distribution in alkaline lake sediments across Tibetan Plateau. Environmental Microbiology, 14(9): 2457-2466.

Zeglin L H, Dahm C N, Barrett J E, et al. 2011. Bacterial community structure along moisture gradients in the parafluvial sediments of two ephemeral desert streams. Microbial Ecology, 61(3): 543-556.

Zhang W, Zhang G S, Liu G X, et al. 2012. Bacterial diversity and distribution in the southeast edge of the Tengger Desert and their correlation with soil enzyme activities. Journal of Environmental Sciences, 24(11): 2004-2011. 